\title{
RECENT LIFE ASSESSMENT TECHNOLOGY FOR EXISTING STEAM TURBINES
}

\author{
K. Saito ${ }^{1}$, A. Sakuma ${ }^{1}$ and M. Fukuda ${ }^{2}$ \\ ${ }^{1}$ Turbine Design and Assembling Dept., Toshiba Corporation, Yokohama 230-0045, Japan \\ ${ }^{2}$ Thermal Power Service Dept., Toshiba Corporation, Tokyo 105-8001, Japan
}

\begin{abstract}
A large and growing portion of electricity is produced by aging thermal power plants. Although excellent, high quality materials such as $\mathrm{CrMoV}$ steel and $12 \% \mathrm{Cr}$ steel, etc. are used for the steam turbines, various forms of metallurgical degradation, due to creep and fatigue, etc. affect the parts and components during long-term operation at high temperature. Extending the life of steam turbines and ensuring high reliability requires life assessment technology, scheduled repairing, conversion, modification and upgrading of components in order to provide a stable power supply. As the high temperature parts and components of aged steam turbines are mainly metallurgically damaged by creep, fatigue and the interaction of both, life assessment combined with analytical and nondestructive methods is essential for realizing strategic plant life extension. We have developed a life assessment technology that takes material degradation into consideration, and has applied the procedure to more than 650 units and 2500 components since 1983. A rotor bore replication device was developed in 1989 for the purpose of nondestructive observation of creep voids and supporting the validity of life prediction results. This paper describes the technical features and applied experience of recent life assessment technology for existing high temperature steam turbines.
\end{abstract}

\section{INTRODUCTION}

Most parts and components of steam turbines, as shown in Figure 1, are made of steels containing various amounts of the principal alloying elements chromium, molybdenum, vanadium and nickel, etc. Most high temperature rotors, valves and blades, etc. are made of high strength materials such as $\mathrm{CrMoV}$ steels and $12 \% \mathrm{Cr}$ steels , but these materials are metallurgically degraded under long-term operation at high temperature. Existing steam turbines are required to operate under severe conditions now and in the future, which means that the inevitable accelerated deterioration of their parts and components such as high-pressure rotors and casing, etc. must be compensated.

There are three kinds of examination method for metallurgical damage assessment as shown in Table 1 , that is, the destructive method, the nondestructive method and the analytical method, but they are not always effective and accurate due to their individual advantages and disadvantages. First of all, although the destructive method can directly evaluate the metallurgical property in laboratory testing devices, sample taking is extremely limited as operations because of the shape and construction of parts and components, and in addition, the analytical method must be used in combination in order to establish the test conditions. Secondly, among the several

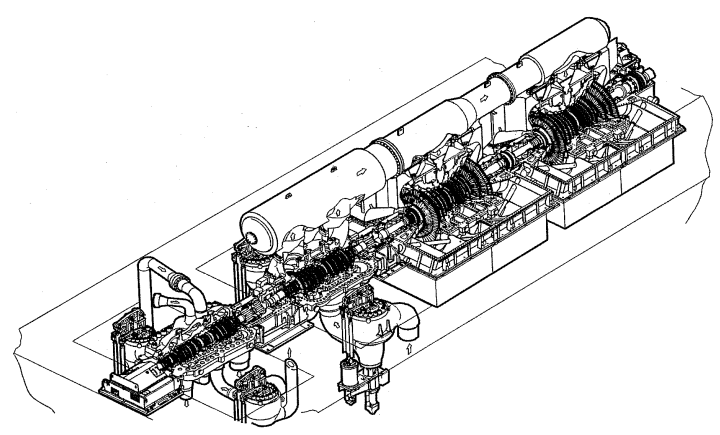

Figure 1: Overview of 700MW class steam turbine. 
nondestructive methods, hardness testing and replica examination are convenient and familiar, but there is room for improvement in evaluating process and precision, because both methods are problematic in relation to shapes and construction. Finally, as analytical methods can obtain the analytical Table 1: Comparison among life assessment methods temperature and stress distribution in the parts and components by using finite element analyses, they are effective to evaluate the residual life and future estimate, but there are pending issues between the evaluation and the actual metallurgical property.

On the other hand, the combined method with the analytical and nondestructive methods is the most effective and useful in order to evaluate residual life as well as the cumulative damage due to creep, fatigue and the interaction of both, in combination with the numerous destructive examination results that are obtained from actual retired rotors, casings, valves and so on.

\section{MATERIAL DEGRADATION OF STEAM TURBINES}

Table 2 shows the potential damage mechanisms and typical remedial actions pertaining to the high temperature parts and components of steam turbines. From the viewpoint of material mechanical property, softening and reduction in the strength of forged, rolled and casted parts and components such as rotors, blades, bolts, casings and valves are caused by creep or fatigue due to high temperature, stress, long-term operation and/or many start-ups and shut-downs.

Table 2: Damage location, mechanisms and remedies for steam turbines

\begin{tabular}{|c|c|c|c|c|c|}
\hline \begin{tabular}{|l|}
$\begin{array}{l}\text { Ports and } \\
\text { components }\end{array}$ \\
\end{tabular} & Location & Typical damage & \begin{tabular}{|l|l|} 
Remedial \\
Action
\end{tabular} & $\begin{array}{l}\text { Following action } \\
\text { Regular inspection }\end{array}$ & \begin{tabular}{|l|l|}
$\begin{array}{l}\text { Definition of } \\
\text { Limit for usage }\end{array}$ \\
\end{tabular} \\
\hline \multirow{3}{*}{ HIP rotor } & Wheel groove & Low cycle fatigue & Skin peeling & Non-destructive & $\begin{array}{l}\text { When skin peeling is no longer practicable. } \\
\text { And/or material has significant deterioration. }\end{array}$ \\
\hline & Center bore & \begin{tabular}{|l|} 
Creep \\
Low cycle fatigue
\end{tabular} & $\begin{array}{l}\text { Overboring } \\
\text { Or newly replace }\end{array}$ & Ditto & $\begin{array}{l}\text { When overboring is no longer practicable. } \\
\text { And/or any abnormality appears in detailed } \\
\text { inspection. }\end{array}$ \\
\hline & Wheel dovetail & \begin{tabular}{|l|}
$\begin{array}{l}\text { Creep } \\
\text { High cycle fatigue }\end{array}$ \\
\end{tabular} & Skin peeling & Ditto & $\begin{array}{l}\text { When crack initiation is anfirmed. } \\
\text { And/or any abnormality appears in detailed } \\
\text { inspection }\end{array}$ \\
\hline \multirow{2}{*}{$\begin{array}{l}\text { HIP inner } \\
\text { casing }\end{array}$} & Inner surface & $\begin{array}{l}\text { Low cycle fatigue } \\
\text { Creep }\end{array}$ & Skin peeling & $\begin{array}{l}\text { Non-destructive } \\
\text { Test }\end{array}$ & $\begin{array}{l}\text { When skin peeling is no longer practicable. } \\
\text { And/or material has significant deterioration. }\end{array}$ \\
\hline & Female thread & $\begin{array}{l}\text { High temperature } \\
\text { creep }\end{array}$ & Oversizing & Ditto & When oversizing is no longer practicable. \\
\hline \multirow{2}{*}{$\begin{array}{l}\text { HIP outer } \\
\text { casing }\end{array}$} & Inner surface & $\begin{array}{l}\begin{array}{l}\text { Low cycle fatigue } \\
\text { Creep }\end{array} \\
\end{array}$ & Skin peeling & $\begin{array}{l}\text { Non-destructive } \\
\text { Test }\end{array}$ & $\begin{array}{l}\text { When skin peeling is no longer practicable. } \\
\text { And/or material has significant deterioration. }\end{array}$ \\
\hline & Outer surface & Creep & Skin peeling & Ditto & Ditto \\
\hline \multirow{2}{*}{ Main valves } & Body & \begin{tabular}{|l|} 
Creep \\
Low cycle fatigue \\
\end{tabular} & Skin peeling & Non-destructive test & $\begin{array}{l}\text { When skin peeling is no longer practicable. } \\
\text { And/or material has significant deterioration. }\end{array}$ \\
\hline & Female thread & Creep & Oversizing & Ditto & When oversizing is no longer practicable. \\
\hline HIIP blades & $\begin{array}{l}\text { Tenon, shroud } \\
\text { cover, dovetail }\end{array}$ & \begin{tabular}{|l|} 
Creep \\
High cycle fatigue \\
\end{tabular} & Newly replace & $\begin{array}{l}\begin{array}{l}\text { Non-destructive test } \\
\text { and visual inspection }\end{array} \\
\end{array}$ & $\begin{array}{l}\text { When cracks have initiated. } \\
\text { And/or any abnormal }\end{array}$ \\
\hline \begin{tabular}{|l|} 
HIP nozzle \\
diaphragm \\
ing
\end{tabular} & Diaphragm & Creep deformation & Skin peeling & Visual inspection & $\begin{array}{l}\text { When skinpeeling is no longer } \\
\text { practicable. }\end{array}$ \\
\hline $\begin{array}{l}\text { HIP casing } \\
\text { bolts }\end{array}$ & Thread & Creep & Newly replace & Non-destructive test & When crack initiation is anticipated. \\
\hline
\end{tabular}

To be more precise, creep rupture property and low cycle fatigue life are reduced at high temperature in couple with material softening, as shown in Figure 2 and Figure 3, which are given by the material tests of the several retired rotors, casing and valves made of CrMo steel, $\mathrm{CrMoV}$ steel and $12 \mathrm{Cr}$ steel, etc [1][2]. As for microstructural change, carbide coarsening in the grain and grain boundary occur due to thermal aging at the high temperature and low stress portion, on the other hand creep voids are formed at high temperature and high stress portion, as shown in figure 4 . And with regard to material toughness, the fracture resistance is reduced by temper

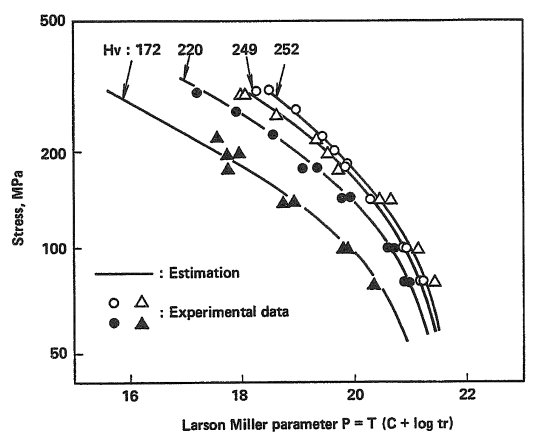

Figure 2: Creep rupture properties depending on hardness for $\mathrm{CrMoV}$ steel 
embrittlement at high temperature portion after long-term operation. Figure 5 shows embrittlement of a retired rotor, that is, the test results of the fracture appearance transition temperature (FATT) and the fracture toughness [1][3].

Thus, softening and embrittlement in the parts and components of steam turbines progress with long-term exposure to high temperature and high stress, accompanied by changes in material property. The numerous destructive examination results that are obtained from the retired rotors, casings and valves, etc. are essential and useful in combined use with nondestructive measurement of softening and embrittlement for life assessment of aged existing steam turbines.

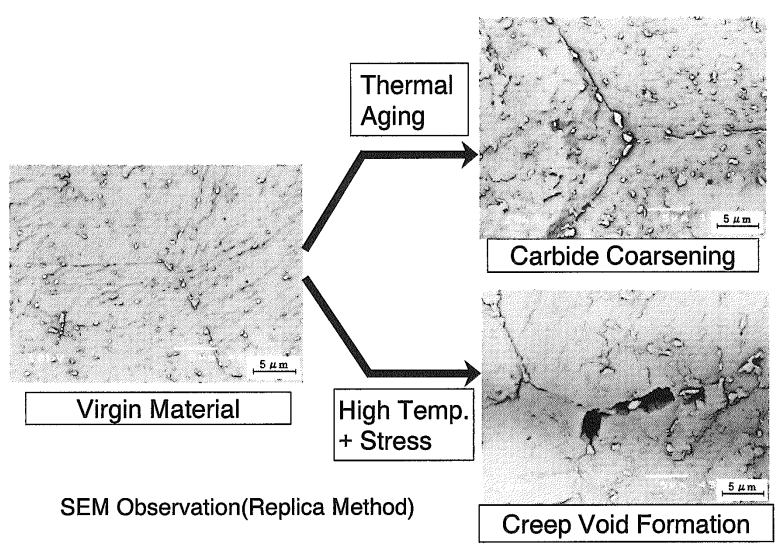

Figure 4: Example of microstructural changes caused by aged deterioration.

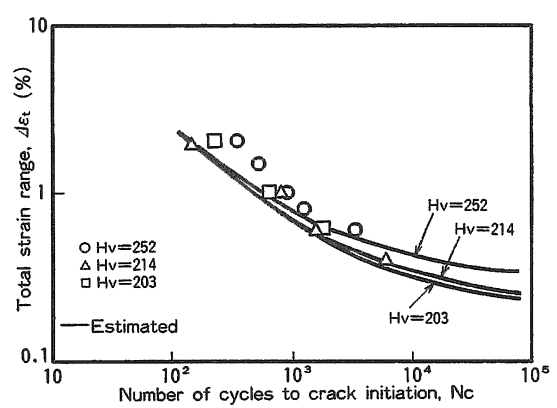

Figure 3: Low cycle fatigue properties depending on hardness for CrMoV steel.

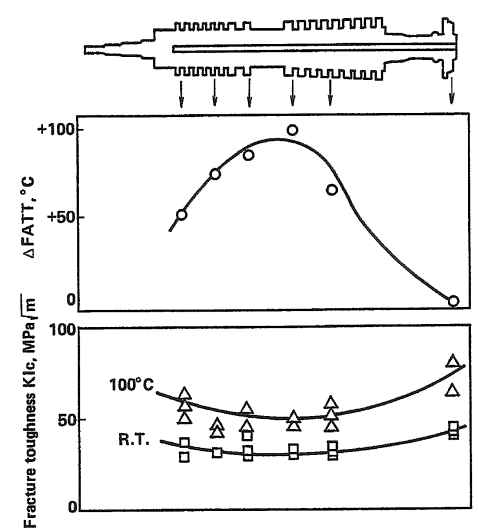

Figure 5: Embrittlement of a retired HIP rotor

\section{TECHNICAL FEATURE OF LIFE ASSESSMENT}

Figure 6 shows the outline of the life assessment which consists of crack initiation life and crack growth life [1] [2]. Temperature and stress distribution on the parts and components are calculated by the finite element method (FEM) by using operating condition and unit service history. Degraded material properties such as high temperature creep strength, low cycle fatigue strength, toughness and metallurgical microstructure are detected by nondestructive measurement of hardness inspection, embrittlement inspection and replica examination.

The cumulative damage due to creep and/or low cycle fatigue is expressed by the following equations, respectively.

$$
\phi_{c}=\frac{t}{t r} \quad \cdots \cdots(1) \quad \phi_{f}=\sum_{i} \frac{n_{i}}{N_{f i}}
$$

where, $\varphi \mathrm{c}:$ consumed life due to creep damage, $\varphi \mathrm{f}:$ consumed life due to fatigue damage, $\mathrm{t}:$ total operation hours, $\operatorname{tr}$ : creep rupture time of material, ni : the number of unit start up and shut down, $\mathrm{Nfi}$ : the number of cycles to fatigue crack initiation of material, i : unit start up mode. 


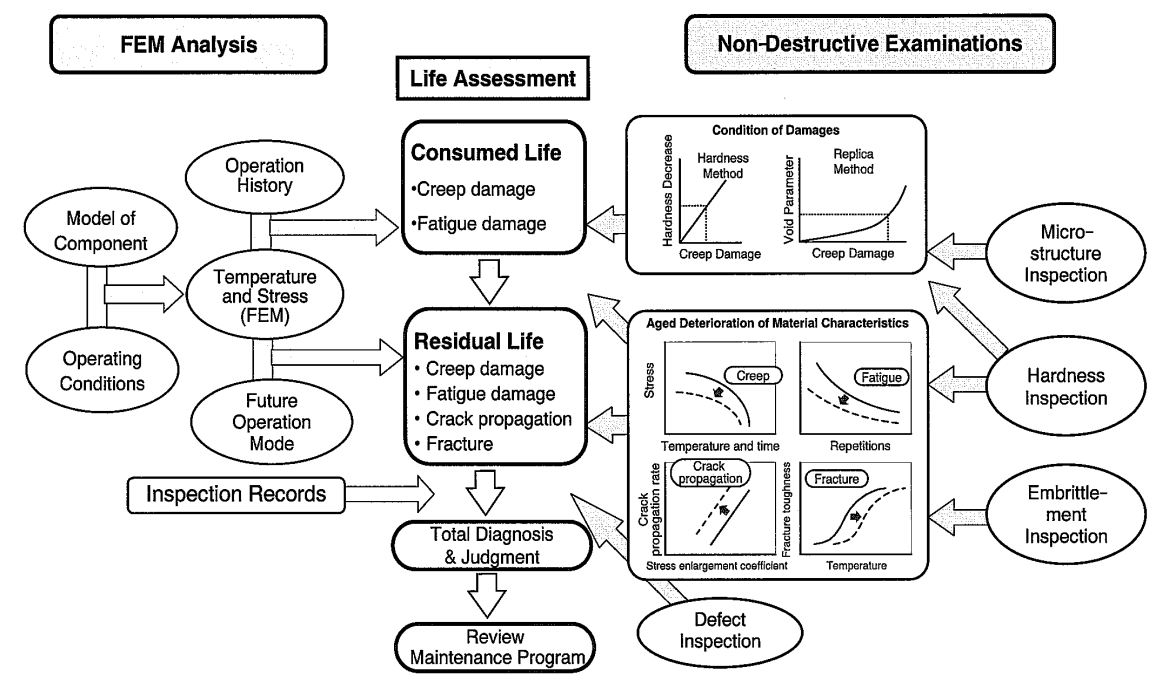

Figure 6: Life assessment methodology for steam turbines

As the critical damage value that causes an initial crack on the material varies depending on the combination of $\varphi \mathrm{c}$ and $\varphi \mathrm{f}$, where sum is 1 (one) or less, the residual life can be predicted under the condition of the degraded material properties. The damage envelope with experimental data for $\mathrm{CrMoV}$ steel is shown in Figure 7. This diagram significantly points out strong interaction feature between creep damage and fatigue damage, and remarkable acceleration of crack initiation by adding a small amount of fatigue damage to creep damage. An accurate evaluation of interaction effect of creep damage and fatigue damage is significant for steam turbine components, where the both kind of damages are superimposed [4].

Crack growth rate due to creep and/or low cycle fatigue,

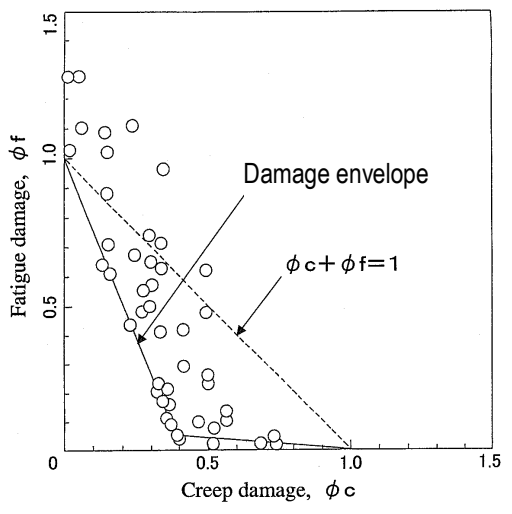

Figure 7: Damage limit diagram for CrMoV steel which is assessed by fracture mechanics are expressed by the following equations, respectively.

$$
\frac{d a}{d t}=A_{o} \cdot \mathrm{K}^{m} \quad \cdots \cdots(3) \quad \frac{d a}{d N}=C_{o}(\Delta \mathrm{K})^{\mathrm{n}}
$$

Where, a: crack depth, $\frac{d a}{d t}$ : amount of crack growth per time, $\frac{d a}{d N}$ : amount of crack growth per stress cycle, $\mathrm{K}:$ stress intensity factor, $\Delta \mathrm{K}$ : stress intensity factor range, Ao, $\mathrm{m}, \mathrm{Co}, \mathrm{n}:$ material constants depending upon the degree of embrittlement.

As mentioned above, as creep damage, fatigue damage and interaction of both are estimated based on the degraded material properties such as Figure 2 and Figure 3, crack initiation life, that is, residual life is predicted reflecting the subsequent operating plan. And furthermore, as the deteriorated fracture resistance is estimated based on the degraded material property such as Figure 5, crack growth life, that is, crack propagation is also simulated.

In these ways, total synthetic judgement as the life diagnosis is performed based on all obtained information and the maintenance program is reviewed. 


\section{APPLIED EXPERIENCE OF LIFE ASSESSMENT FOR EXISING STEAM TURBINES}

Figure 8 shows an example of life diagnosis results for a high and intermediate pressure outer casing of $\mathrm{CrMoV}$ cast steel [5]. The critical area is at the crotches between main steam inlet and hot reheat inlet on the outer surface of the lower half casing, and its consumed life was estimated to $\varphi \mathrm{c}=1.3$ due to creep damage and $\varphi \mathrm{f}=0.01$ due to fatigue damage, respectively, that is its residual life was predicted to be none. Then, according to this diagnosis result, detailed inspection of the above mentioned surface was carried out at the next overhaul period, and a crack of $100 \mathrm{~mm}$ length was detected.

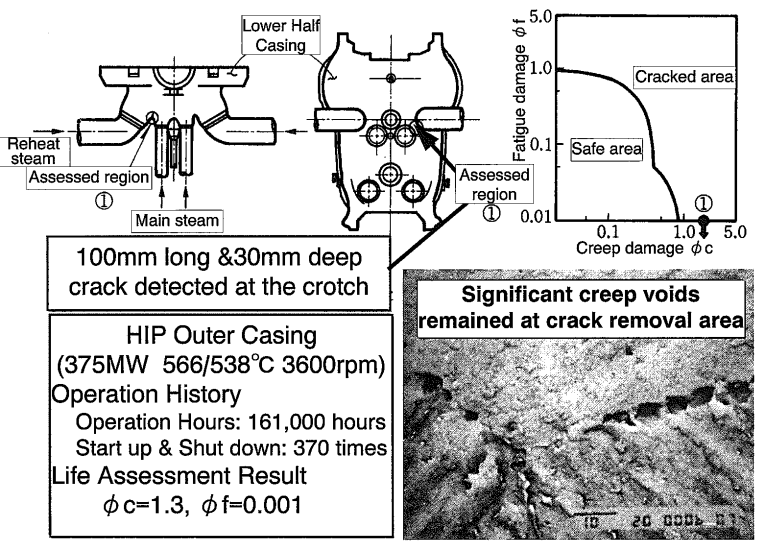

Figure 8: Example of life assessment for steam turbine casing Although the crack was removed by skin peeling off up to $30 \mathrm{~mm}$ depth until no indication was observed by magnetic particle inspection, microstructure inspection of the replica method indicates significant creep voids remained at the crack removal area. It means this area was mainly composed of creep damage in spite of no magnetic particle indication.

Figure 9 shows another example for an intermediate pressure rotor of $\mathrm{CrMoV}$ forged steel. Its consumed life was estimated at $\varphi_{c}=0.89$ due to creep damage and $\varphi \mathrm{f}<0.01$ due to fatigue damage at center bore potion of this rotor, respectively. The microstructure of the area that is shown in Figure 9 was detected by using the rotor bore replication device shown in Figure 10. Replication technique was difficult to applying because of small bore diameter, but we have developed it in 1989, enabling observation of the metallurgical structure precisely [6].

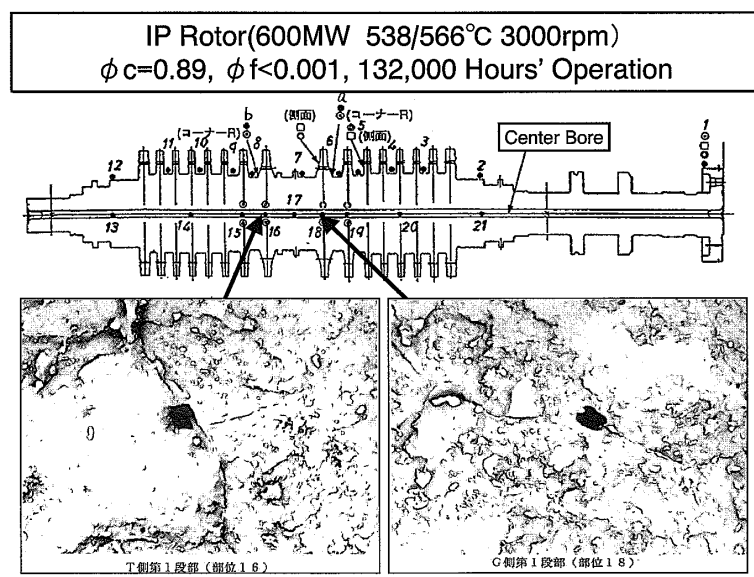

Figure 9: Example of life assessment for steam turbine rotor

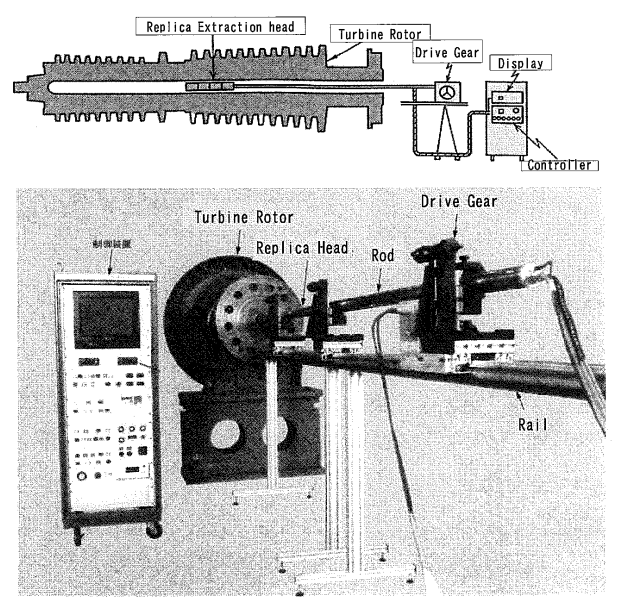

Figure 10: Configuration of rotor bore replication device 


\begin{abstract}
The creep voids shown in Figure 9 support the validity of diagnostic results. The residual life is also predicted from the consumed life, and subsequent progress of creep void formation could be explained by "A" parameter under the high temperature creep condition as shown in Figure 11.

These components mentioned above have been replaced because their remaining life

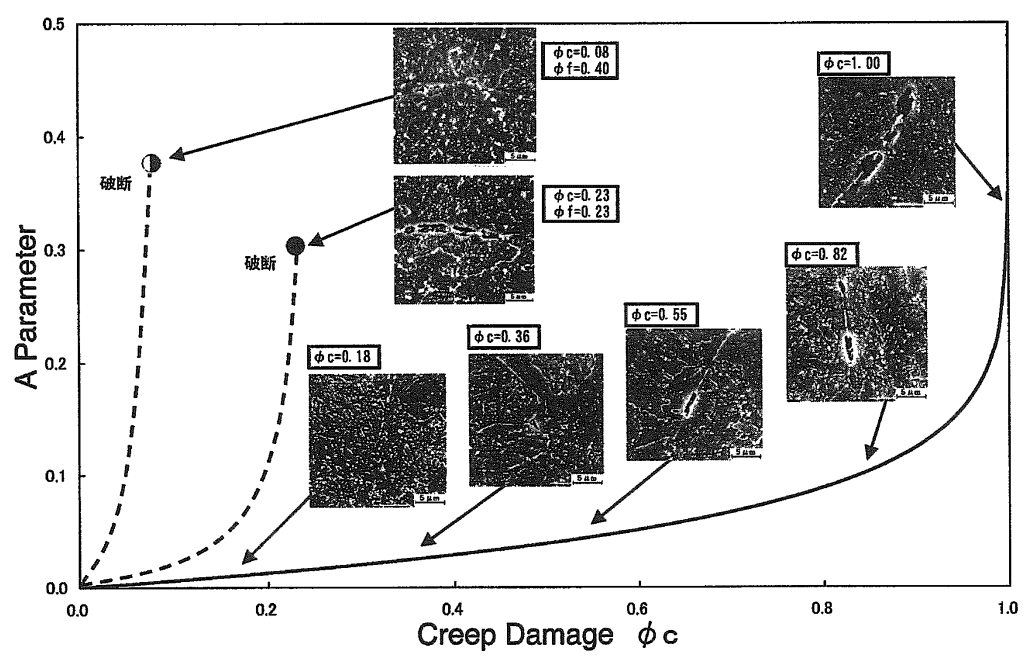

Figure 11: Relationship between "A" parameter and creep damage for $\mathrm{CrMoV}$ rotor steel

were judged to be insufficient based on the results of life diagnosis. Newly replaced components are applied to modified design and the latest manufacturing process to contribute to extend the life of steam turbines.
\end{abstract}

\title{
5 CONCLUSION
}

In order to provide a stable power supply, high reliability and high maintainability are requisite conditions for steam turbines. And at the same time, effective life assessment is important to ensure that existing units undergo scheduled maintenance and life extension strategies [7]. We are continuing to develop and design further effective and useful life assessment technologies for steam turbines and their auxiliary equipment based on the experience from existing units.

\section{REFERENCES}

[1] Kimura, K., Fujiyama, K., Saito, K. and Muramatsu, M., Conference on Life Extension and Assessment of Fossil Plants, EPRI, Washington, D.C., June 2-4, 1986.

[2] Fujiyama, K., Kimura, K., Muramatsu, M. and Kashiwaya, H., et al., Proceedings of International Conference on Life Assessment and Extension, pp. 20-30, Hague, June 13-15, 1988.

[3] Saito, K., Kimura, K., Muramatsu, M., Kashiwaya, H., Shoji, T. and Takahashi, H. et al., Fossile Plant Inspection Workshop, EPRI, San Antonio, September 9-11, 1986.

[4] Curran, R.M. and Wundt, B.M., Publication MPC-8, ASME, pp. 218-314, 1978.

[5] Fujiwara, T. and Fujiyama, K., Toshiba Review, Vol. 44, No.6, pp. 490-493, 1989.

[6] Saito, K. and Sakamoto, H., Toshiba Review, Vol. 46, No.6, pp. 491-494, 1991.

[7] Sakuma, A., Takahashi, T., Fujiwara, T. and Fukuda, M., JSME International, Series B, Vol. 45, No. 3, pp. 492-498, 2002. 